\title{
SISTEMAS DE AGRICULTURA URBANA NA REGIÃO CENTRAL DE PALMAS, TOCANTINS: CONVENCIONAL OU AGROECOLÓGICA?
}

Urban agriculture in central region of Palmas, Tocantins: conventional or agroecological?

DOI: 10.48075/igepec.v25i1.25339

Alessandra Polastrini

Claudia Regina de Sousa e Silva

João Aparecido Bazzoli 


\title{
AGRICULTURA URBANA NA REGIÃO CENTRAL DE PALMAS, TOCANTINS: CONVENCIONAL OU AGROECOLÓGICA?
}

\author{
Urban agriculture in the central region of Palmas, Tocantins: \\ conventional or agroecological?
}

\subsection{5/igepec.v25i1.25339}

\author{
Alessandra Polastrini \\ Claudia Regina de Sousa e Silva \\ João Aparecido Bazolli
}

\begin{abstract}
Resumo: Objetivou-se com esta pesquisa analisar se as hortas urbanas na região central de Palmas, se enquadram no sistema convencional ou agroecológico. Foram pesquisadas quatro hortas, localizadas nas quadras 1006, 1106, 1206 e 1306 Sul. A pesquisa consistiu em aplicação de questionários a 42 horticultores e entrevista a dois servidores de órgãos ligados ao programa Hortas Urbanas. O estudo apontou que existe uma incongruência entre o quantitativo de horticultores cadastrados e aqueles que trabalham nas hortas. O horticultor é, majoritariamente, do sexo feminino, de baixa renda e baixa escolaridade. Verificou-se a utilização de produtos incompatíveis com a produção agroecológica. Porém, há um processo de transição do convencional, pois observou-se apropriação de técnicas de manejo baseados na agroecologia. Há fiscalização e assistência técnica, todavia, estas acontecem em número insuficiente para garantir adequada orientação do horticultor e garantir a qualidade dos produtos ao consumidor. São necessários mais estudos e atenção do Poder Público.
\end{abstract}

Palavras-chaves: Desenvolvimento urbano. Horticultor. Segurança alimentar. Hortas comunitárias.

Abstract: The aim of this research was to analyze if urban gardens in the central region of Palmas fit into the conventional or agroecological system. Four gardens were surveyed, which are located in blocks 1006, 1106, 1206 and 1306 South. The survey consisted of the application of questionnaires to 42 horticulturists and interviews with two government employees linked to the Urban Gardens program. The study pointed out that there is an inconsistency between the number of registered horticulturists and those who work in vegetable gardens. The horticulturist is mostly female, with low income and low schooling. The use of products incompatible with agroecological production was verified. However, there is a transition process from the conventional model, since there was an appropriation of management techniques based on agroecology. There is inspection and technical assistance, but these happen insufficiently to guarantee the horticulturist's adequate orientation and to guarantee the quality of the products to the consumer. More studies and attention from the government are needed.

Key words: Urban development. Horticulturist. Food safety. Community vegetables gardens.

Resumen El objetivo de esta investigación fue analizar si los huertos urbanos en la región central de Palmas se ajustan al sistema convencional o agroecológico. Se investigaron cuatro huertos, ubicados en los bloques 1006, 1106, 1206 y 1306 Sur. La investigación consistió en cuestionarios a 42 horticultores y entrevistas con dos servidores públicos vinculados al programa Urban Gardens. El estudio señaló que existe una inconsistencia entre el número de horticultores registrados y los que trabajan en los huertos. El horticultor es principalmente femenino, con bajos ingresos y bajo nivel educativo. Se verificó el uso de productos incompatibles con la producción agroecológica. Sin embargo, hay un proceso de transición del convencional, ya que hubo una apropiación de técnicas de manejo basadas en la agroecología. Hay inspección y asistencia técnica, pero esto ocurre en un número insuficiente para garantizar la orientación adecuada del horticultor y garantizar la calidad de los productos al consumidor. Se necesitan más estudios y atención gubernamental.

Palabras clave: Dessarrollo urbano. Horticultor. Seguridad alimentar. Huertos comunitários. 
Informe GEPEC, ISSN:1679-415X, Toledo, v. 25, n.1, p. 143-163, jan./jun. 2021. 


\section{INTRODUÇÃO}

A globalização, característica marcante do mundo atual, tem evidenciado problemáticas também globalizadas. As denominadas "cidades ocultas" refletem as 800 milhões de pessoas que vivem em condições de vida inadequadas, tidas como urbanas, e que não são contabilizadas pelas estatísticas oficiais (FAO, 2019). A imagem do urbano, que outrora era sinônimo de emprego, renda, segurança alimentar e qualidade de vida, deu lugar a um cenário de importante desigualdade e exclusão social.

Skar et al. (2020) afirmam que os desafios futuros à urbanização são diversos ao mesmo tempo que complexos. Poluição, degradação ambiental, transporte de grandes massas populacionais, bem como de produtos necessários ao seu abastecimento, gestão de resíduos, escoamento de águas das chuvas, produção de alimento suficiente para essa população crescente e disponibilidade de água potável, são exemplos de alguns dos principais desafios (UNITED NATIONS, 2018). Adicionase a isso, o fato de que as cidades absorverão a maior parte do crescimento populacional esperado para as próximas décadas e, como acréscimo, há ainda a continuidade do êxodo rural (UNITED NATIONS, 2018).

Diante disso, observa-se que nos países em desenvolvimento, incluindo o Brasil, os padrões urbanos de alimentação estão se modificando acentuadamente, saindo dos alimentos tradicionais e saudáveis, para aqueles processados, com altos teores de açúcares, gorduras, sal e, reconhecidamente, pobres em nutrientes necessários à saúde humana (FAO, 2019).

Sabe-se também que na zona urbana, a população pobre é ainda mais vulnerável à escassez de alimento, pois são dependentes de renda, trabalho e preços dos alimentos e, por outro lado, o acesso às terras produtivas, trabalho e comida é limitado (FAO, 2019).

Nesse contexto, é importante que se atente para a produção agrícola, criação de animais e cultivo de árvores realizados nas cidades ou em seus arredores, atividade denominada como agricultura urbana e periurbana (AUP), ou agricultura e silvicultura urbana. Definida como o "cultivo de árvores, alimentos e outros produtos agrícolas e criação de animais dentro ou às margens das cidades", a atividade que mais se destaca é a horticultura (RUAF FOUNDATION). Além de ser uma atividade promovida no espaço urbano, a AUP conta fundamentalmente com recursos e mão de obra urbanos, exercendo influência direta no centro urbano o qual está implantada (RUAF FOUNDATION).

No Brasil, a agricultura urbana vem ganhando espaço nas últimas décadas. Com o intuito de reduzir a pobreza e a insegurança alimentar entre a população mais carente do país, nasceu o Programa Nacional de Agricultura Urbana e Periurbana, criado pelo Ministério do Desenvolvimento Social (SOUSA, 2019). Outro grande avanço foi a instituição da Política Nacional de Agroecologia e Produção orgânica (Pnapo) por meio do Decreto $\mathrm{n}^{\circ}$ 7.794, de 20 de agosto de 2012, alicerçando políticas de fomento à uma produção voltada para a saúde e sustentabilidade ambiental e social (BRASIL, 2012).

Em Palmas, capital do Tocantins, o projeto das hortas urbanas surgiu em 1992. Com uma proposta voltada para o âmbito social, as hortas urbanas comunitárias têm promovido segurança alimentar, incrementos na renda das famílias, integração social e melhorias no ambiente urbano no decorrer de quase três décadas. Destarte, a cidade apresenta ainda a maior população do estado, são cerca de 300 mil habitantes (SIDRA, 2020). Destes, muitos vieram de outros municípios, ou mesmo estados e países, em busca de emprego, acesso às universidades, tratamento de saúde e outras 
oportunidades de melhorias na qualidade de vida. Mas uma parcela considerável dessa população tem baixo poder aquisitivo e, portanto, as hortas são uma alternativa importante de trabalho, renda e produção de alimento saudável.

Todavia, apesar dos benefícios da AUP, existem barreiras ao sucesso do projeto e que podem até mesmo comprometer seus potenciais benefícios. Devido as particularidades do ambiente urbano, como a maior concentração de residências e pessoas, o uso de agrotóxicos e domissanitários, por exemplo, constituem uma prática de manejo que traz impactos fortemente negativos, colocando em risco a saúde de horticultores, moradores circunvizinhos às hortas e consumidores.

Nesse sentido, há uma lacuna com relação ao sistema adotado nas hortas comunitárias. Nestas são utilizados defensivos ou domissanitários? O sistema adotado é o tradicional ou agroecológico? Há algum tipo de fiscalização nesse sentido? Os horticultores recebem capacitação a respeito dos riscos do uso de agrotóxicos e as formas alternativas de controle de pragas e doenças?

Estas interrogações levantadas nortearam o desenvolvimento desta pesquisa e, buscando respondê-las, este estudo objetivou analisar se as hortas urbanas na região central de Palmas, se enquadram no sistema convencional ou agroecológico.

O presente artigo está estruturado da seguinte forma: Além desta introdução, segue-se uma revisão bibliográfica sobre a agricultura urbana. A terceira seção descreve a metodologia adotada para alcançar o objetivo da pesquisa. Os resultados são apresentados na quarta seção e, por fim, a quinta seção que descrevem as conclusões da pesquisa.

\section{REVISÃO DE LITERATURA}

\section{AGRICULTURA URBANA}

A agricultura urbana envolve uma série de atividades produtivas no meio urbano e/ou periurbano e engloba, genericamente, produção animal e vegetal (RUAF FOUNDATION). Diante dos desafios urbanos da atualidade, e que tendem a se agravarem no futuro, a agricultura urbana tem sido cada vez mais reconhecida como uma alternativa para integrar soluções nos aspectos social, econômico e ecológico das cidades (FAO, 2019; UNITED NATIONS, 2018).

O percentual de urbanização no mundo, que em 2018 era de 55,3\%, alcançará o patamar médio de 68,4\% em 2050, sendo que nas regiões mais desenvolvidas aproximará os 90\% (UNITED NATIONS, 2018). Os dados causam preocupação e evidenciam o cenário desafiador que é esperado para as próximas décadas, especialmente, no que se refere à alimentação dessa gigantesca população urbana. $\mathrm{O}$ desenvolvimento futuro exige uma sistemática que vise soluções inovadoras e sustentáveis, relocalização do sistema alimentar e o conceito de cidade circular, asseveram Skar et al. (2020).

Na cidade, a população pobre é mais dependente de trabalho e renda, e também, é vulnerável às crises e oscilações nos preços de gêneros alimentícios, devido a fatores como a falta de terras produtivas e de espaços disponíveis para a agricultura (UNITED NATIONS, 2018). Neste sentido, atualmente cada vez mais instituições governamentais e não governamentais, pesquisadores e outros atores da sociedade têm incentivado a agricultura urbana como caminho para gerar múltiplos efeitos positivos de transbordamento no ambiente urbano.

A princípio, o benefício primordial da agricultura urbana é a produção de alimentos, com o intuito de melhorar a segurança alimentar de famílias pobres da zona 
urbana. O Relatório final do $\operatorname{CONSEA}(2015$, p.26) coloca o alimento como "patrimônio sociocultural" e reafirma a necessidade de incentivo à produção agroecológica e sustentável, promovendo a saúde da sociedade e do planeta.

Entretanto, Sousa e Madureira vão além e destacam o "caráter potencialmente multifuncional, já que ultrapassa a mera produção de alimentos" (2017, p.323). Agricultura urbana gera emprego, incrementa a renda de famílias pobres, contribui para que os envolvidos tenham hábitos de vida saudável, promove uma reeducação alimentar e ambiental, redução da obesidade, melhoria no paisagismo e na estética das cidades, favorece o controle de doenças como dengue e zika, além de pragas como baratas, escorpiões e caramujos.

A agricultura urbana permite o melhor aproveitamento de espaços comumente ociosos, que não raramente são meios de danos à sociedade. Vazios urbanos podem acumular lixo, plantas daninhas, abrigar criminosos, comprometer esteticamente o ambiente urbano. Assim, com a implantação de hortas nestes espaços, registra-se, por exemplo, melhorias em fatores como sanidade, ecologia e até mesmo na segurança pública. Abou; Yabi; Ogouwale (2018) também ressaltaram as vantagens da agricultura urbana e periurbana para a sociedade. Conforme os autores, na África Ocidental o peso da agricultura é muito grande e, de maneira geral, nos países em desenvolvimento o impacto é ainda mais profundo. Para Giacchè e Porto, as hortas em plenas cidades podem oferecer "uma solução para um conjunto de problemas sociais, ambientais e econômicos enfrentados na cidade pelos diversos órgãos internacionais, governos nacionais, locais e diversas organizações da sociedade civil” (2015, p. 45).

No Brasil, de modo semelhante ao observado em outros países, a agricultura urbana cada vez mais ocupa posição de destaque em debates políticos e estudos científicos. O país, especialmente após a revolução verde, está marcado pelo vigoroso agronegócio, que apesar de ter elevado drasticamente a produção e produtividade de alimentos e movimentar efetivamente a economia nacional, caracteriza-se por ser um sistema altamente excludente e pouco sustentável. Esse sistema levou um grande número de produtores familiares ao endividamento, pobreza e venda da propriedade, pois não conseguiam competir com os grandes produtores. Como consequência, uma grande massa populacional abandonou (e ainda abandona) o campo em busca de trabalho, renda e oportunidades de melhoria na qualidade de vida na zona urbana.

Todavia, na cidade, essa população enfrenta outros desafios iguais ou até mais importantes que aqueles do ambiente rural, pois há muita dependência da renda oriunda de um emprego para garantirem sua subsistência. Além disso, há questões que estão cada vez mais em pauta atualmente, como a sustentabilidade ambiental e a qualidade dos alimentos, que tem posto em xeque a viabilidade e os benefícios do agronegócio a curto, médio e longo prazo no Brasil, país cuja economia é essencialmente agrária. Desmatamento, uso exacerbado de agrotóxicos, extinção de espécies animais e vegetais, contaminação de ar, água e solo, alterações climáticas, monocultura, perda da biodiversidade e desigualdade social são alguns exemplos de impactos negativos do agronegócio.

Neste contexto, a agricultura urbana no Brasil passou a receber maior atenção e a se desenvolver nas últimas décadas. De acordo com Sousa (2019), houveram iniciativas tanto governamentais como não governamentais. A nível federal, as hortas urbanas passaram a fazer parte do Programa Nacional de Agricultura Urbana e Periurbana, criado em 2018 pelo Ministério do Desenvolvimento Social. Também existem iniciativas similares nos âmbitos estaduais e municipais, somando-se assim mais de 600 unidades de agricultura urbana e periurbana distribuídas pelo território brasileiro (SOUSA, 2019). 
No município de Palmas, o projeto de Hortas Urbanas surgiu em 1992, sendo gerido pela Prefeitura de Palmas por meio da Secretaria Municipal de Desenvolvimento Rural (SEDER). As primeiras hortas foram implantadas nos bairros Aureny III, 1106 Sul e 307 Norte com o intuito de melhorar os aspectos sociais e econômicos da população pobre que chegava na mais nova capital em busca de oportunidades de trabalho (SOUSA, 2019). A cidade de Palmas, inaugurada em 1989, foi a última cidade brasileira a ser planejada no último século. Apresenta uma posição geográfica privilegiada, funcionando como um elo de ligação entre a região Norte e as demais regiões do país.

Em 1994 o projeto foi ampliado, criando hortas em várias regiões da cidade. Em 22 de junho de 2012 foi instituído o regulamento próprio através do Decreto Municipal $\mathrm{n}^{0}$ 284, de 22 de junho de 2012 (PALMAS, 2012). Por meio do dispositivo, horticultores passaram a ter seus direitos e deveres, relativos às hortas, documentados. Atualmente, somam-se 23 hortas comunitárias ativas na capital (PALMAS, 2020).

A SEDER é responsável por auxiliar os produtores, fornecer assistência técnica e providenciar a estrutura básica das hortas, como água, preparo do solo e cerca de alambrado. Eventualmente, há a distribuição de sementes, adubos e equipamentos aos horticultores. A assistência técnica é voltada para a transferência de tecnologia para uma produção agroecológica. Para isso, são realizadas palestras, cursos, capacitações e dias de campo com os horticultores. O intuito é transferir a eles o conhecimento necessário sobre o controle alternativo de pragas e doenças, visando uma produção agroecológica, preservando a saúde de horticultores, moradores próximos às hortas e consumidores.

De acordo com Sousa (2019), apenas 20\% das hortas comunitárias fazem uso de agrotóxicos. Sobretudo nas zonas urbanizadas, devido a maior aglomeração de residências e famílias, a exposição à agrotóxicos e seus efeitos são ainda mais preocupantes e indesejados, pois afetam um número maior de pessoas. Nesse sentido, Ribeiro, Bógus e Watanebe asseveram que a AUP no sistema agroecológico "pode ser considerada uma ferramenta de promoção da saúde" (2015, p. 741, tradução nossa).

Conforme diagnóstico de Sousa (2019), outra iniciativa importante e voltada para a produção agroecológica em Palmas se refere ao reaproveitamento de podas e cortes de plantas na cidade. O que antes era um problema, então tratado como lixo, atualmente é utilizado para compostagem e é fornecido aos horticultores das hortas comunitárias para adubação orgânica de hortaliças e plantas medicinais.

De acordo com levantamento da SEDER em 2016, o programa beneficiava mais de 400 famílias sendo um importante aliado na geração de renda. Dentre as principais hortaliças cultivadas pelos beneficiários do programa estão cebolinha, coentro, couve, alface, rúcula, e ervas medicinais. A produção é comercializada diretamente ao consumidor nas próprias hortas, ou por meio dos minis supermercados e feiras (PALMAS, 2016). 


\section{AGRICULTURA CONVENCIONAL VERSUS AGROECOLÓGICA}

A agricultura passou por intensas transformações nos últimos cem anos, especialmente o processo denominado de "Revolução Verde", que no Brasil ganhou força a partir de 1960 (SAMBUICHI et al., 2017). Houve uma marcante modernização, alta especialização produtiva, intensificação dos sistemas de produção e a incorporação de elementos do setor industrial à agricultura. Todavia, agricultura convencional, embora tenha contribuído sobremaneira para o aumento da produção de alimentos, transformando-os em commodities, elevado substancialmente o produto interno bruto (PIB) e promovido o superávit na balança comercial brasileira, as externalidades impactam negativamente a sociedade e o meio ambiente (SAMBUICHI et al., 2017). Esse modelo hegemônico de agricultura tornou o país o maior mercado de agrotóxicos do mundo. As monoculturas legitimaram danos ambientais e perdas na biodiversidade dos biomas brasileiros.

No âmbito socioeconômico, o desenvolvimento econômico balizado pela agricultura convencional não refletiu em um desenvolvimento social equitativo, inclusivo e justo. Mas, em uma acentuação do êxodo rural em decorrência da concentração fundiária, descapitalização do produtor familiar e incapacidade de quase 90\% dos pequenos estabelecimentos em competir com grandes produtores (SAMBUICHI et al., 2017). O êxodo rural, destarte, tem aumentado as taxas de urbanização se desdobrando em múltiplos problemas urbanos que se agravam cada vez mais (SKAR et al., 2020; UNITED NATIONS, 2018).

Em razão disso, fortes críticas a esse modelo de agricultura concatenaram movimentos de resistência em prol da agricultura familiar, do desenvolvimento social, da produção sustentável e da proteção ambiental. Nesse sentido, nas últimas décadas vem crescendo o interesse e a difusão da produção agroecológica. Esta se fundamenta em princípios alicerçados no bem-estar social e na sustentabilidade ambiental. Dessa forma, valoriza a socialização, os povos tradicionais e seus saberes, a articulação entre comunidade, Estado e conhecimento acadêmico-científico, a soberania alimentar, equidade de gênero, preservação de espécies animais e vegetais e uso de sementes crioulas, utilização dos recursos disponíveis, prevalência do emprego de métodos biológicos e mecânicos para controle de pragas, doenças e invasoras, rotação de culturas, entre outros (SAMBUICHI et al., 2017).

Há um debate conflituoso no Brasil com relação as diferenças entre sistemas orgânico e agroecológico (ANJOS; CALDAS, 2017). O sistema agroecológico inclui outros aspectos além das agronômicas, que é o foco da agricultura orgânica. Já agroecologia perpassa por esferas mais amplas como a cultura dos povos tradicionais e seus desdobramentos na forma de produzir vegetais, por exemplo (ANJOS; CALDAS, 2017; LIMA et al., 2020).

Em 2003 foi instituída a Lei $\mathrm{n}^{\circ} 10.831$, que dispõe sobre a agricultura orgânica no Brasil (BRASIL, 2003). Nesta, o conceito de sistema orgânico abarca diferentes sistemas produtivos, incluindo o agroecológico (LIMA et al., 2020). Este representou um passo importante para a agricultura alternativa. Quase 10 anos depois, em 20 de agosto de 2012, o Decreto $\mathrm{n}^{\circ} 7.794$ instituiu a Política Nacional de Agroecologia e Produção orgânica, o que balizou o crescimento da produção agroecológica no país (BRASIL, 2012). O programa é destaque mundial em política agroambiental e é modelo para aprendizados e intercâmbio de instituições e experiências (LIMA et al., 2020). Esse arcabouço legal projetou o Brasil como um dos países que mais evoluiu em âmbito agroambiental (LIMA et al., 2020). 
De qualquer modo a agricultura alternativa, seja ela orgânica ou agroecológica, tem apresentado demanda e mercado crescentes, considerando os dados mais sólidos que se referem à agricultura orgânica (FIBL, 2020). Foi constatado um aumento de 2 milhões de hectares de terras agrícolas orgânicas em 2018 (FIBL; IFOAM, 2020, p. 20). A América Latina concentra $11 \%$ das terras orgânicas do mundo e a Argentina, Uruguai e Brasil são os países líderes no continente com 3,6, 2,1 e 1,2 milhões de hectares cultivados de modo orgânico. Conforme o documento, no Brasil "a demanda vem de uma classe média crescente que busca alimentos saudáveis e nutritivos” (p. 27, tradução nossa).

Para Ludewigs, o Brasil tem "um potencial de desenvolvimento da agricultura agroecológica em razão de suas dimensões territoriais, sua tradição agrícola e a disponibilidade de recursos naturais" (2014, p. 20, tradução nossa). Porém, apesar das vantagens competitivas, o país apresenta barreiras consideráveis ao crescimento da produção agroecológica/orgânica, especialmente a presença do grande latifúndio e do monocultivo (LIMA et al., 2020). O que tem limitado o aumento da produção nacional.

Não há dados concretos da produção nacional da agricultura alternativa. Entretanto, os registros obrigatórios dispostos pela legislação vigente evidenciam que são 22 mil unidades de produção orgânica e 17 mil produtores no país, o que representa um crescimento de aproximadamente $20 \%$ na última década (LIMA et al., 2020). A região nordeste lidera a concentração de produção orgânica, seguida das regiões sul e sudeste, respectivamente. Mas não existe uma discriminação segura de quais produtos são produzidos e o volume da produção.

\section{3-METODOLOGIA}

A pesquisa apresentou abordagem qualitativa e foi desenvolvida entre agosto e dezembro de 2019. O estudo consistiu na aplicação de questionários estruturados à horticultores das hortas comunitárias da região central de Palmas, capital do Tocantins e entrevista semiestruturadas à atores envolvidos no projeto das Hortas Urbanas. Esse foi o método escolhido em função de permitir o contato do pesquisador com o objeto pesquisa, permitindo compreender o ambiente analisado, a realidade social dos respondentes e entrevistados e por permitir registros e a coleta de informações adicionais importantes para o estudo.

Foi realizada pesquisa bibliográfica e documental, as quais permitiram um maior conhecimento acerca da AUP em seu contexto geral, compreender suas vantagens e desvantagens, bem como as políticas públicas de incentivo existentes atualmente e as barreiras ao seu sucesso de implementação e desenvolvimento. Esse trabalho, também norteou a elaboração dos questionários e das guias de entrevistas, instrumentos de coleta de dados primários desta pesquisa.

Procedeu-se o levantamento das hortas e número de horticultores existentes na região central da capital. O número de horticultores cadastrados é de 86 (oitenta e seis), sendo 18, 31, 12 e 25 horticultores das quadras 1006, 1106, 1206 e 1306 sul, respectivamente (SEDER). As entrevistas aconteceram com um funcionário da SEDER e um da Agência de Defesa Agropecuária do Estado do Tocantins (ADAPEC), as quais foram realizadas após contato prévio por e-mail e telefone. Registra-se ainda que as perguntas de entrevista foram também enviadas via Sistema de Informação ao Cidadão e e-mail à SEDER.

Em relação aos horticultores, aponta-se que houve uma incompatibilidade no que se refere ao número de horticultores cadastrados na SEDER e o quantitativo encontrado por meio da aplicação dos questionários. O número real de horticultores 
ativos é menor que os registrados oficialmente pela SEDER. Não foi possível quantificar com exatidão pois, os acordos entre os próprios horticultores na transferência de canteiros e a impossibilidade de localização de cada horticultor inviabilizou essa documentação do quantitativo real. Somaram-se 59 horticultores localizados, contatados e convidados a participarem da pesquisa. Destes, 42 (quarenta e dois) aceitaram participar. A localização do município e das hortas comunitárias da região central estão ilustradas no mapa de localização na Figura 1.

Figura 1 - Mapa de Localização das Hortas Comunitárias Pesquisadas

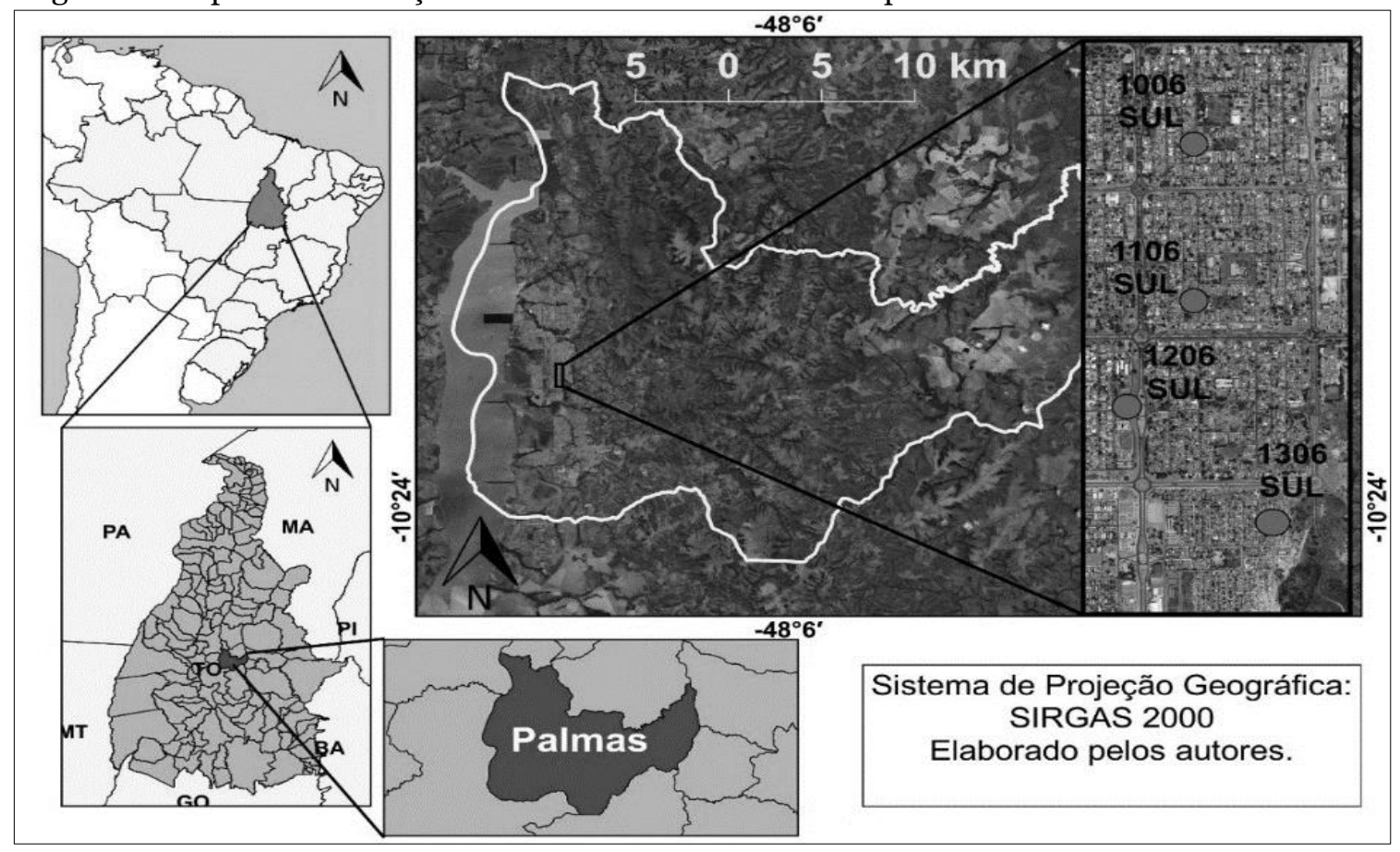

Fonte: Elaborado pelos autores

Em relação aos horticultores, primeiramente foi aplicado o pré-teste na horta da 1206 Sul com o intuito de aprimorar a coleta de dados, tornando-a mais eficiente e eficaz. O experimento inicial permitiu modificações na versão final do questionário tornando-o mais objetivo, contemplando todos os aspectos necessários ao adequado desenvolvimento da pesquisa.

As visitas foram realizadas in loco sem aviso prévio para aplicação dos questionários. Essas visitas aconteceram nos horários que os horticultores trivialmente estão presentes nas hortas, ou seja, entre $7 \mathrm{~h}$ e 10h da manhã e das 16h30 às 18h30 da tarde. Foi efetuada a abordagem e o convite para participar do estudo, mediante assinatura em duas vias do Termo de Consentimento Livre e Esclarecido, garantindo a segurança, anonimato dos respondentes e a ética da pesquisa.

A classificação final das hortas em agroecológica ou convencional se deu, especialmente, por meio da definição de sistema orgânico de produção agropecuário, descrito no art. $1^{\circ}$ da Lei $\mathrm{n}^{\circ}$ 10.831, de 23 de dezembro de 2003, que abrange a produção agroecológica desse sistema de produção (BRASIL, 2003).

Por seguinte, para a análise dos dados colhidos acerca do perfil dos produtores e da produção e comercialização, bem como a descrição dos fenômenos observados, os mesmos foram tabulados no Excel. Para melhor observação e apresentação dos resultados também foram elaborados gráficos a partir dos dados tabulados no Excel. 


\section{4 - RESULTADOS E DISCUSSÃO}

Nesta seção são relatados e discutidos os resultados da pesquisa. Constatou-se que a metodologia adotada foi adequada para que se atingisse o objetivo da pesquisa, definido inicialmente. $\mathrm{E}$ os questionários foram instrumento eficaz para conhecer $\mathrm{o}$ sistema produtivo das hortas comunitárias, bem como o perfil dos horticultores. Já as entrevistas, permitiram uma visão holística da AUP em Palmas, diagnosticando particularidades regionalizadas do projeto.

Em relação à distribuição dos canteiros entre os beneficiários do programa palmense de hortas urbanas, conforme regimento interno, cada família pode dispor de no máximo de 05 (cinco) canteiros. Entretanto, constatou-se a existência de acordos informais realizados entre os horticultores em que os desistentes, que mudam de endereço, estão sem tempo, desmotivados, dentre outras razões, passam seus canteiros a horticultores que estão produzindo de modo ativo na horta. Foi identificada a existência de horticultores utilizando 10 (dez) canteiros ou mais. Dessa forma há horticultores dispondo de um número maior de canteiros, para além do limite regulamentado pela SEDER.

De acordo com o regulamento, em seu art. $7^{\circ}$, inciso VI, o agricultor não poderá "cuidar ou manter outra área ou lote de outro beneficiário por qualquer período, sem a autorização expressa da Administração Pública” (PALMAS, 2012). Essas constatações sugerem que evidências anedóticas estejam sendo negligenciadas pela Administração Pública.

Acrescenta-se ainda que em todas as hortas foi constatada uma maior atividade por parte de alguns horticultores e inatividade de outros. Haviam canteiros onde foi observada a presença de plantas invasoras ou apenas cebolinha verde, cujo trato cultural é menor e a quantidade demandada pelo mercado consumidor menor. Ou seja, a cebolinha ocupa o canteiro de modo a sugerir que este esteja sendo utilizado. No entanto, o solo do canteiro estava seco, o solo mais compactado e visivelmente mais pobre, ou seja, elementos que pressupõe desídia.

Conforme o regulamento, o produtor fere o inciso VIII do art. $7^{\circ}$ ao "deixar os canteiros ociosos por mais de 15 (quinze) dias, mesmo que limpos, salvo os casos devidamente justificados" (PALMAS, 2012). Embora haja aqueles em que estão plantadas cebolinhas, é importante haver um maior controle do uso dos lotes pelos horticultores, pois em caso de desídia outra pessoa necessitada e que enquadre nos requisitos poderia estar trabalhando ativamente nesses canteiros ociosos ou subutilizados.

\section{PERFIL DOS HORTICULTORES}

O perfil dos horticultores urbanos foi abordado no questionário através de questões acerca de gênero, renda, ocupação e escolaridade. Assim sendo, de acordo com os resultados encontrados, a maior parte dos horticultores urbanos, ou seja, 71,4\% (30) dos respondentes eram do sexo feminino, sendo que apenas 28,6\% (12) eram do sexo masculino. Isso evidenciou que as mulheres são as que mais estão ativas na AUP de Palmas. A presença marcante da mulher na agricultura urbana em Palmas é algo recorrente. Gratão et al. (2015) constataram que 76\% dos horticultores eram do sexo feminino. Sousa (2019) diagnosticou um percentual ainda maior de mulheres nas hortas de Palmas, chegando a $78 \%$ do sexo feminino. Essa forte presença feminina na agricultura urbana de Palmas está alinhada ao fundamentado na produção 
agroecológica, que postula a equidade de gênero, promovendo emprego e renda à mulher, inclusão social e oportunidades sociais iguais tanto para homens, quanto para mulheres.

No que se refere a escolaridade, certificou-se que $81 \%$ (34) dos respondentes tinham no máximo o ensino fundamental completo. Apenas $7 \%$ (3) atingiram o ensino médio, 9,5\% (4) chegaram ao nível técnico e 2,4\% (1) alcançaram o nível superior. Nenhum dos respondentes possuíam título de pós-graduação. Estes resultados encontrados evidenciam que a AUP está auxiliando uma parcela da população que possui menor nível de escolaridade, o que torna ainda mais positivo o programa de AUP, pois melhora a renda, o acesso à cursos, formação e interação social. Os resultados encontrados são semelhantes aos diagnosticados por Sousa (2019), que evidenciou que os horticultores tinham, de modo geral, o ensino fundamental. Conforme o descortinado por Gratão et al. (2015), 60,5\% dos horticultores tinham o ensino fundamental incompleto. O Gráfico 1 apresenta a escolaridade dos horticultores.

Gráfico 1 - Nível de Escolaridade dos horticultores das Hortas Pesquisadas.

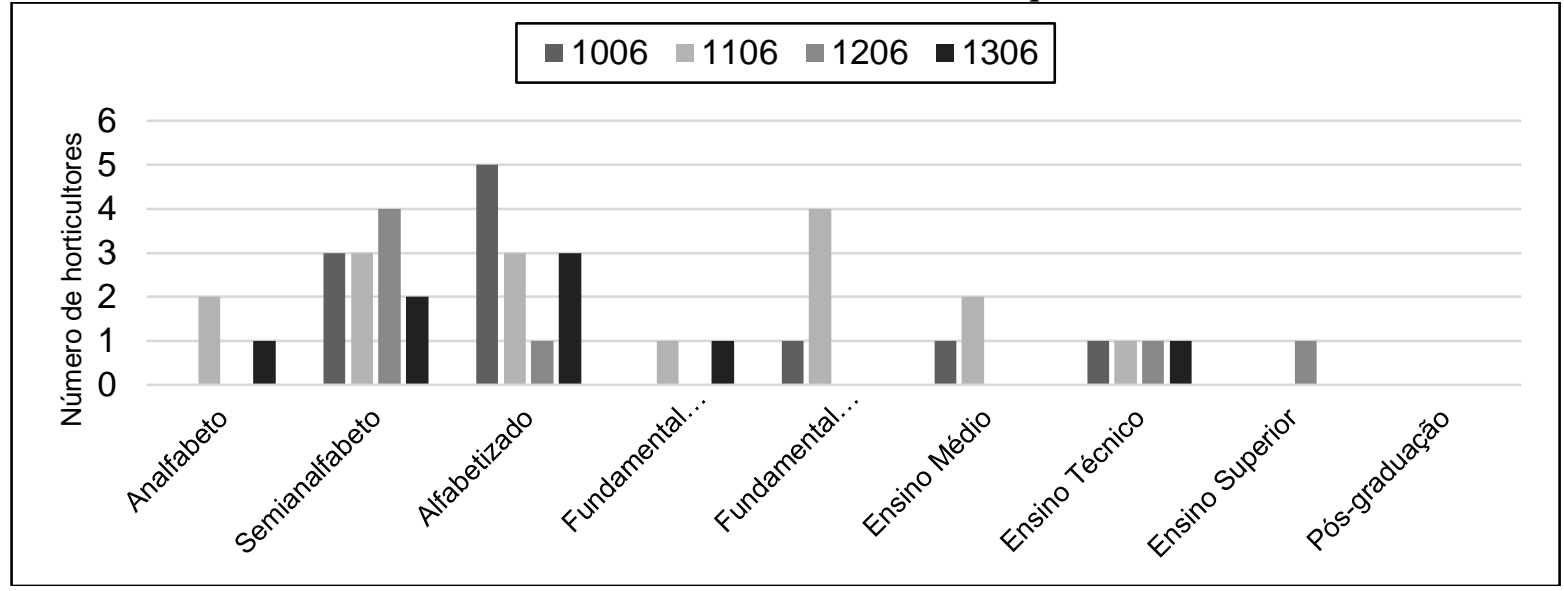

Fonte: Dados da pesquisa

O nível de escolaridade influencia no tempo dedicado à agricultura (SOUSA, 2019). Afeta ainda, negativamente, a empregabilidade e o salário dos trabalhadores. A agricultura urbana em Palmas reflete em benefícios sociais expressivos, atenuando a plangência dos problemas sociais da zona urbana.

A maior parte dos horticultores estão na faixa etária entre 40 e 70 anos (98\%). Gratão et al. (2015) encontraram que $45 \%$ dos horticultores estavam na faixa etária dos 51 aos 69 anos. Sousa (2019) também confirma que os horticultores apresentam idade, geralmente, superior aos 40 anos.

As famílias dos horticultores não são grandes, pois a média averiguada foi de 3,7 pessoas por família. Acrescenta-se ainda que, 93\% (39) dos horticultores não dependem exclusivamente da renda obtida pela comercialização da produção da horta. Mais da metade dos horticultores são aposentados ou recebem auxílio doença (52\%). Os demais são, majoritariamente, microempreendedores individuais ou trabalhadores informais como pedreiro, diarista/doméstica. Apenas um respondente era servidor público municipal.

Ressalta-se aqui a importância da renda da AUP como complemento na renda total da família. Embora 7\% (3) dos respondentes sejam dependentes dela para subsistência, tornando o programa (horta urbana) ainda mais relevante no aspecto social, devido a limitação de espaço para cada grupo familiar, a produção final não é 
substancial a ponto de alimentar a família do agricultor e ainda gerar uma valor da produção que garanta a qualidade de vida adequada a todo grupo familiar. Conforme relatado pelos próprios horticultores, o valor oriundo da AUP é insuficiente para garantir um orçamento adequado ao final do mês.

Esses resultados estão de acordo com os encontrados por Gratão et al. (2015), Valadares (2016) e Sousa (2019). Os autores também relataram que a maioria dos horticultores não são dependentes da renda da produção vegetal da AUP, mas que estas são um complemento importante à renda familiar.

\section{PRODUÇÃO E COMERCIALIZAÇÃO}

Nas hortas pesquisadas são cultivadas, principalmente, hortaliças e ervas medicinais/aromáticas. Em todas as hortas avaliadas (1006, 1106, 1206 e 1306 Sul) a alface, a couve e o cheiro verde (salsa, cebolinha e coentro) ocupam a maior parte dos canteiros existentes. Também há a produção de rúcula e brócolis, embora em menor escala. Estas espécies são as mais demandadas e, conforme os horticultores, "tem boa saída" para a comercialização. Sousa (2019) também destacou que as principais espécies cultivadas são a alface, a couve e cheiro verde. O tamanho da área das hortas, forma, número de canteiros e tamanho dos canteiros variam bastante, conforme pode ser constatado na Figura 2.

Figura 2 - Área das hortas e número de canteiros.

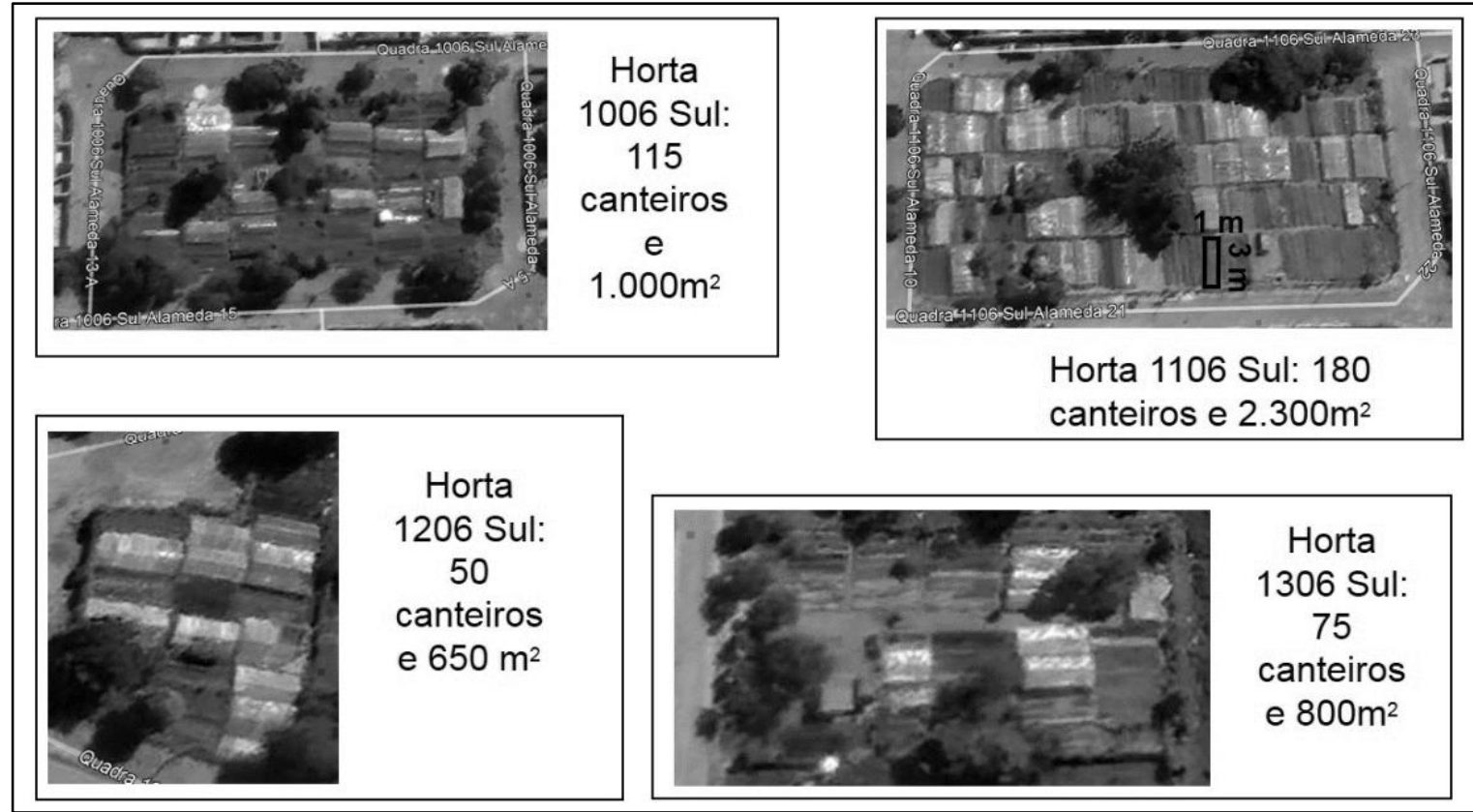

Fonte: Dados da pesquisa

A produção dessas espécies trivialmente é assíncrona em função, especialmente, do clima. No período chuvoso a produção de alface, por exemplo, é consideravelmente menor pelos horticultores. A razão é que a maioria das hortas não possui estrutura para barrar a força das chuvas torrenciais que prejudicam o cultivo dessa hortaliça nesse período. Assim, a produção está imbricada à demanda local e às condições produtivas.

Entre as ervas medicinais/aromáticas foram encontradas: alecrim, erva cidreira, capim cidreira, alfavaca, manjericão, folha santa, hortelã, poejo, arruda e boldo. Estas são destinadas ao consumo dos horticultores e seus familiares e venda 
direta na horta, com algumas nuances (o caso de apenas dois horticultores). Em pesquisa em hortas ativas de Palmas, Gratão et al. (2015) encontraram hortelã, mastruz e malva.

Sistematicamente, os horticultores afirmaram que a horticultura lhes faz bem nos mais diversos aspectos, tais como: saúde física, psicológica, segurança alimentar, inclusão social e melhoria financeira. Tais benefícios são confirmados pelos resultados robustos da literatura acadêmica e na experiência de pesquisadores e gestores públicos, como as externalidades positivas da AUP.

Todavia, paradoxalmente, há dificuldades e barreiras a continuidade e expansão da AUP em Palmas. Adicionado ao já exposto na subseção anterior, que envolve problemas relativos à gestão e fiscalização das hortas comunitárias, há problemas quanto ao sistema produtivo.

$\mathrm{Na}$ teoria, as hortas comunitárias devem ser agroecológicas, uma vez que na AUP existem maiores aglomerados urbanos e, portanto, um agravamento das externalidades negativas referente ao uso de defensivos químicos na produção vegetal. Os horticultores negaram a utilização de quaisquer agrotóxicos, afirmando serem proibidos. Mas, foram encontradas embalagens vazias de domissanitários em duas das quatro hortas pesquisadas.

Resultados encontrados por Valadares (2016) refutam a hipótese de ausência de aplicação de agrotóxicos nas hortas urbanas, uma vez que foi identificado que 42,22\% dos horticultores faziam uso de tais produtos. A autora ainda ressaltou que o regulamento descreve que o uso de tais produtos deve ser a "última forma para a contenção de possíveis pragas, no entanto deve ser realizada apenas como a autorização da Gestão do Programa, com restrito acompanhamento especializado" (VALADARES, 2016, p. 26).

Com base nos resultados encontrados e munidos pela legislação vigente e pela literatura científica (GRATÃO et al., 2015; VALADARES, 2016; SOUSA, 2019), foi constatado que as hortas pesquisadas ainda não podem ser classificadas como agroecológicas. As mesmas estão numa fase de transição do sistema convencional para o agroecológico, o que é configurado como positivo e altamente benéfico para os atores envolvidos. O Quadro 1 proporciona uma análise refinada e estruturada das características da agricultura urbana convencional, agroecológica e quais são comuns às hortas pesquisadas.

Informe GEPEC, ISSN:1679-415X, Toledo, v. 25, n.1, p. 143-163, jan./jun. 2021. 
Quadro 1 - Caracterização das Hortas Pesquisadas com Base na Lei n ${ }^{\circ} 10.831$.

\begin{tabular}{|l|c|c|c|}
\hline \multicolumn{1}{|c|}{ Aspectos analisados } & Agroecológica & Convencional & $\begin{array}{c}\text { Hortas } \\
\text { Analisadas }\end{array}$ \\
\hline Uso dos recursos naturais disponíveis & Sim & Não & Parcialmente \\
\hline $\begin{array}{l}\text { Uso dos recursos socioeconômicos } \\
\text { disponíveis }\end{array}$ & Sim & Não & Parcialmente \\
\hline $\begin{array}{l}\text { Respeito à integridade cultural das } \\
\text { comunidades }\end{array}$ & Sim & Não & Parcialmente \\
\hline Sustentabilidade ecológica & Sim & Não & Parcialmente \\
\hline Benefícios sociais & Sim & Não & Sim \\
\hline Dependência de energia não-renovável & Não & Sim & Não \\
\hline $\begin{array}{l}\text { Prevalência do emprego de métodos } \\
\text { biológicos e mecânicos }\end{array}$ & Sim & Não & Sim \\
\hline Emprego de Agrotóxicos/domissanitários & Não & Sim & Sim \\
\hline Uso de fertilizantes sintéticos & Não & Sim & Sim \\
\hline Organismos geneticamente modificados & Não & Sim & Sim \\
\hline Equidade de gênero & Sim & Não & Sim \\
\hline
\end{tabular}

Fonte: Baseado na Lei ${ }^{\circ}$ 10.831, de 23 de dezembro de 2003 (BRASIL, 2003)

$\mathrm{O}$ art. $6^{\circ}$ do regulamento estabelece como deveres dos horticultores zelar pela limpeza ambiental, a qualidade dos produtos produzidos e "utilizar agrotóxicos apenas com a autorização da Gestão do Programa e o devido acompanhamento especializado ou técnico" (PALMAS, 2012). Neste sentido, a Gestão do Programa (GP) estabelece a busca por uma produção voltada para o sistema agroecológico, evitando uso de fertilizantes químicos e agrotóxicos. Horticultores das quatro hortas comunitárias relataram que frequentemente há problemas com pragas e doenças nas olerícolas. Todos os horticultores negaram a utilização de qualquer tipo de defensivo agrícola no controle das mesmas e afirmaram fazerem uso de defensivos alternativos a base de fumo (Nicotina tabacum), neem (Azadirachta indica A. Juss), cal virgem, sabão de coco e arruda (Ruta graveolens). Além disso, declararam realizar um manejo que auxilie na profilaxia e no controle de pragas e doenças, como a eliminação de plantas doentes e a catação manual de insetos que prejudicam o cultivo, por exemplo.

Entretanto, em entrevista à ADAPEC, foi relatado que durante fiscalização e inspeção orientativa em hortas urbanas e rurais do município de Palmas foi diagnosticada uma incongruência dissuasiva. O resultado dessa ação foi a constatação de irregularidades importantes como a utilização de domissanitários e o seu armazenamento irregular. Segundo o órgão, "particularmente na horta da 1106 Sul foi detectado o Diazinon, um inseticida organofosforado utilizado para controlar pragas urbanas como baratas e que tem um período de carência longo, implicando em resíduos nas hortaliças”, explicou.

Essa ação da ADAPEC resultou em um relatório descrevendo os pormenores. Neste, foi ressaltada que essa prática é "imensamente prejudicial à produção das olerícolas, uma vez que essas espécies vegetais são consideradas de ciclo curto e os produtos domissanitários e/ou de uso veterinários são fabricados para proporcionarem um alto resíduo ao longo do tempo" (ADAPEC, 2019, p.1). Também foi descrito que os moradores circunvizinhos às hortas reclamaram de odor forte, característico de produto químico. A ADAPEC, como órgão égide, procedeu a orientação dos horticultores acerca dos riscos à saúde e das sanções e punições caso esse manejo errôneo persista e sejam encontrados resíduos acima do permitido. 
As fiscalizações e orientações se mostram efetivas pois, descortinam as incongruências existentes, legitimando e ratificando a segurança ou insegurança da produção. Porém, verifica-se que estas inspeções acontecem em um número ainda aquém do necessário. Esse fato também foi constatado por Valadares (2016), cuja pesquisa apresentou maior abrangência, incluindo todas as hortas ativas (17) no período de análise.

A fonte de nutrientes para adubação das culturas vem da compostagem fornecida pela prefeitura, aquisição individual de casca de arroz e esterco de animais. Apesar dessas matérias não terem como origem um sistema agroecológico, estão mais voltadas para uma produção sustentável e "limpa" por não utilizarem largamente fertilizantes químicos. Resultados contrários foram encontrados por Sousa (2019), pois os horticultores respondentes admitiram fazer uso de fertilizantes químicos, descortinando formas exóginas de aquisição de nutrientes que não são condizentes com o sistema agroecológico. Também Valadares (2016) constatou que 100\% dos horticultores utilizavam fertilizantes químicos.

Esses resultados contraditórios podem ser explicados pelas pesquisas terem sido feitas em anos diferentes e, principalmente, pela abordagem de horticultores diferentes e em hortas diferentes. Nas visitas in loco às hortas foi observado que há diferenças nas hortas. Algumas apresentavam cobertura dos canteiros sendo que em outras praticamente não existiam cobertura nos canteiros. Também se verificou uma tendência da horta da 1006 Sul mais voltada para uma produção agroecológica. Isso sinaliza que não se pode generalizar o cenário produtivo, mas o consumidor pode fazer a aquisição de produtos da horta e do horticultor que ele mais confia na qualidade da produção.

De qualquer forma, as hortas comunitárias pesquisadas ainda não podem receber o título de agroecológicas pois seria uma denominação indébita, pelo menos até o presente momento. Em contrapartida, as mesmas já implantaram diversas medidas compatíveis com os princípios da agroecologia e, consequentemente, usam menos agrotóxicos, fertilizantes químicos e herbicidas para controlar plantas invasoras.

Para fins de agregação de valor, abertura de novos mercados e qualidade da produção, é interessante que a transição para a produção agroecológica aconteça o mais breve possível. E que mecanismos de garantia dessa produção "limpa e sustentável”, por meio de sistemas participativos ou mesmo certificação, sejam providenciados, através da união dos atores dessa cadeia e Poder Público.

Para evitar o uso de produtos inadequados às culturas cultivadas nas hortas, é de capital importância a assistência técnica aos horticultores. Apesar da SEDER possuir agrônomos disponíveis para atender aos horticultores, $7 \%$ destes responderam que não recebem assistência técnica. E, entre aqueles que a recebem, 90,5\% afirmaram ser insatisfatória a assistência técnica fornecida pela SEDER.

As pragas mais citadas foram lagarta, mosca branca, lesma e pulgão. Quando questionados se alguma medida preventiva era tomada para evitar essas pragas, 86\% afirmaram não tomar qualquer medida preventiva. Em contrapartida, no controle de plantas invasoras, 98\% declararam que as medidas de combate são executadas manualmente.

Vale aqui ressaltar que é possível o cultivo de hortaliças livres de agrotóxicos. Para Michereff Filho et al. (2013), etapas como monitoramento, manejo ambiental, reconhecimento de pragas e seus inimigos naturais e seleção do método adequado de controle do problema enfrentado são essenciais para tornar a produção agroecológica. Entretanto, é preciso que haja um manejo adequado que só pode acontecer, de fato, se 
os que trabalham na atividade possuírem conhecimento suficiente para aplicação de técnicas necessárias. Nesta direção tem-se o manejo profilático que busca evitar ou atenuar a ocorrência de pragas ou doenças (MICHEREFF FILHO et al., 2013).

Em relação à comercialização da produção, verificou-se que os horticultores respondentes não apresentaram ter muito conhecimento de quanto a atividade tem gerado de renda, pois não realizam nenhum tipo de controle das vendas. Este fato também foi constato por Sousa (2019). A autora acrescentou que apesar dos horticultores informarem renda mensal de $\mathrm{R} \$ 1000,00$ com a venda da produção, eles não fazem anotações sólidas e também podem ter ficado intimidados durante a pesquisa e não mencionado o valor absoluto.

Em atenção aos pontos negativos e dificuldades enfrentadas no exercício da atividade, observa-se que houveram horticultores que expuseram suas críticas ao sistema adotado. As mesmas foram em função de a renda proporcionada ser consideravelmente baixa. E também relacionadas à desconfortos físicos causados pelo trabalho diário com as hortaliças, e pela limpeza manual dos canteiros. Entretanto, os casos foram isolados e, de maneira geral, todos afirmaram gostar da agricultura por esta proporcionar bem-estar, fato que é constatado no estudo conduzido por Abou, Yabi e Ogouwale (2018). Assim, tem-se que o manejo profilático é indispensável quando se busca uma agricultura livre de agrotóxicos, no entanto conforme pode ser observado aproximadamente $88 \%$ dos horticultores questionados não o realizam.

Dito isso, menciona-se que apesar de demandar um maior gasto de tempo, além de um trabalho minucioso, a eliminação das invasoras de modo manual se constitui uma forma totalmente limpa e de acordo com o preconizado nas práticas agroecológicas. Sendo assim, registra-se que ficam isentos os riscos ao trabalhador, ao consumidor e também, ao meio ambiente oriundos de contaminação por produtos químicos.

O programa Hortas Urbanas é altamente benéfico, porém para que não se enfraqueça ou haja desmotivação, mas sim evolução e ampliação do programa, é necessária uma maior atenção do Poder Público quanto a gestão dos recursos, ao cumprimento do regulamento, fiscalização e capacitação dos envolvidos, especialmente os horticultores.

\section{CONCLUSÕES}

O objetivo da pesquisa foi atingido e ao analisar as hortas urbanas na região central de Palmas, foi constatado que ainda não pertencem ao sistema agroecológico e estão em transição entre o convencional e o agroecológico. Aplicações de técnicas agronômicas mais sustentável e utilizando recursos disponíveis, bem como a preocupação com o desenvolvimento social e o respeito ao meio ambiente estão presentes nas hortas pesquisadas. Porém, alguns aspectos ainda precisam ser melhorados para que de fato sejam hortas classificadas como agroecológicas, de acordo com a legislação vigente.

Não houve indicativos de uso de agrotóxicos nas hortas pesquisadas, porém, marcas pontuais do uso de domissanitários foram confirmadas durante as visitas e aplicação dos questionários. Em entrevista, essa informação foi advogada pelo órgão fiscalizador que ressaltou ainda a gravidade dessa prática, acarretando em riscos iminentes a horticultores, consumidores e à população circunvizinha às hortas urbanas. Também foi confirmada a existência de fiscalização das hortas tanto urbanas quanto rurais, o que é muito positivo e reflete em maior segurança aos entes envolvidos. 
Os horticultores tem recebido capacitação acerca do controle alternativo de pragas e doenças das olerícolas por meio da SEDER. São realizados eventos, cursos, capacitações e dias de campo com essa finalidade. A adesão e participação dos horticultores ainda está aquém do desejável, o que é agravado pela baixa escolaridade dos mesmos.

A metodologia adotada foi adequada a proposta da pesquisa no tocante a esfera dos sistemas produtivos. Todavia, estudos futuros, incluindo especialmente a análise foliar das plantas cultivadas nas hortas de Palmas, serão essenciais para confirmarem a presença ou ausência de resíduos de agrotóxicos, produtos veterinários ou domissanitários nas espécies produzidas e comercializadas.

Há ações e políticas públicas para a AUP em Palmas. Entretanto, verifica-se que é preciso mais estudos a respeito e maior presença do Poder Público na AUP para fiscalizar, orientar e ratificar o atual contexto do programa e promover evoluções mais consistentes, para que haja uma apropriação urbana efetiva e integral dos potenciais benefícios da AUP.

\section{REFERÊNCIAS}

ABOU, Mouritala; YABI, Ibouraima; OGOUWALE, Euloge. Evaluation de la durabilité agro-écologique des aménagementes hydro-agricoles de la plaine inondable Dans le Tandem Dangbo-Adjohoun au Sud-Est Du Bénin. European Scientific Journal, v.12, n. 9, 2018.

ADAPEC. Relatório de atividade de campo. [Online] Mensagem pessoal. Palmas/TO, 2019. 28 jun. 2020.

ANJOS, Flávio Sacco dos; CALDAS, Nádia Velleda. Uma resposta sólida a um regime agroalimentar em crise: o fenômeno GAS na Itália. Revista Brasileira de Ciências Sociais, São Paulo: v. 32, n. 95, 2017.

BRASIL. Decreto $\mathrm{n}^{\circ}$ 7.794, de 20 de agosto de 2012. Institui a política nacional de agroecologia e produção orgânica. Diário Oficial, Brasília, p.4, 21 ago. 2012.

BRASIL. Lei $\mathrm{n}^{\circ}$ 10.831, de 23 de dezembro de 2003. Dispõe sobre a agricultura orgânica e dá outras providências. Diário Oficial, Brasília, p. 8, 24 dez. 2003.

CONSEA. V Conferência Nacional de Segurança Alimentar e Nutricional. Documento Base, 2015. Disponível em: <https://bityli.com/ObcKQ>. Acesso em: 12 abr. 2019.

FAO, IFAD, UNICEF, WFP and WHO. The State of food security and nutrition in the world 2019. Safeguarding against economic slowdowns and downturns. Rome, FAO, 2019.

FIBL - FORSCHUNGSINSTITUT FÜR BIOLOGISCHEN LANDBAU; IFOAM FEDERAÇÃO INTERNACIONAL DOS MOVIMENTOS DA AGRICULTURA ORGÂNICA. The world of organic agriculture: statistics \& emerging trends 2020. Research Institute of Organic Agriculture FIBL and IFOAM Organics International, 2020. Disponível em: 
<https://www.fibl.org/fileadmin/documents/shop/5011-organic-world-2020.pdf>. Acesso em: 23 jul. 2020.

GIACCHÈ, Giulia; PORTO, Lya. Políticas públicas de agricultura urbana e periurbana: uma comparação entre os casos de São Paulo e Campinas. Informações Econômicas, São Paulo, SP, v. 45, n. 6, 2015.

GRATÃO, Lha; SILVA, Paulo Vitor de Sousa; SOUZA, Géshica Soares; SCHOTT, Eloise; MOREIRA, Renata Andrade de Medeiros; NASCIMENTO, Guilherme Nobrel do. Análise situacional das hortas comunitárias do município de Palmas, Tocantins, Brasil: uma visão etnofarmacológica. Revista Cereus, v.7, n.2, maio/ago., UnirG, Gurupi/TO, 2015.

LIMA, Sandra Kitakawa; GALIZA, Marcelo; VALADARES, Alexandre; ALVES, Fábio. Produção e consumo de produtos orgânico no Mundo e no Brasil. Texto para discussão 2538, Brasília: Rio de janeiro: Ipea, 2020.

LUDEWIGS, Thomas. Políticas Agroambientales em América Latina y el Caribe Análises de casos de Brasil. Programa de Cooperación internacional Brasil Organización de las naciones unidas para la alimentación y la agricultura (FAO), 2014.

MICHEREFF FILHO, Miguel; RESENDE, Francisco Vilela; VIDAL, Mariane Carvalho; GUIMARÃES, Jorge Anderson; MOURA, Alexandre Pinho de; SILVA, Patrícia Santos da. Manejo de pragas em hortaliças durante a transição agroecológica. Circular Técnica n. 119, Embrapa Hortaliças, Brasília - DF, 2013.

PALMAS. Prefeitura Municipal de Palmas. Secretaria municipal de governo. Decreto $\mathbf{n}^{\circ} \mathbf{2 8 4}$, de 22 de junho de 2012. Palmas/TO, 2012.

PALMAS. Prefeitura Municipal de Palmas. Hortas Comunitárias unem moradores e geram renda de mais de $\mathbf{R} \$ 155$ mil. Palmas, 2016. Disponível em:<https://bit.ly/2C8oweV >. Acesso em: 23 de jan. 2019.

PALMAS. Prefeitura Municipal de Palmas. Relação dos endereços das hortas comunitárias. Secretaria de Desenvolvimento Rural - SEDER, Palmas, 2020.

RIBEIRO, Silvana Maria; BÓGUS, Cláudia Maria; WATANABE, Helena Akemi Wada. Agroecological urban agriculture from the perspectve of health promotion. Saúde e Sociedade, v.24, n.2, p.730-743, 2015.

RUAF FOUNDATION. Urban agriculture and city region food systems: what and why -RUAF Urban Agriculture and Food Systems. Disponível em:

<https://ruaf.org/urban-agriculture-and-city-region-food-systems/>. Acesso em: 10 jun. 2020.

SOUSA, Diana; MADUREIRA, Helena. Padrões territoriais da agricultura urbana na cidade do Porto. GOT, Revista de Geografia e Ordenamento do Território, n. 11, p. 309-325, 2017. 
SOUSA, Tatiana de Oliveira. Agricultura urbana e alimentação: análise das hortas urbanas na cidade de Palmas. 2019. 80f. Dissertação (Mestrado) Programa de Pós-Graduação em Desenvolvimento Regional, Universidade Federal do Tocantins, Campus Universitário de Palmas, 2019.

SIDRA, SISTEMA IBGE DE RECUPERAÇÃO AUTOMÁTICA. SIDRA 2020. 2020. Disponível em: <https://sidra.ibge.gov.br/home/ipca/brasil>. Acesso em: 9 mai. 2020.

SAMBUICHI, Regina Helena Rosa; MOURA, Iracema Ferreira de; MATTOS, Luciana Mansor de; ÁVILA, Mário Lúcio de; SPÍNOLA, Paulo Asafe Campos; SILVA, Ana Paula Moreira da. A política Nacional de Agroecologia e Produção Orgânica no Brasil: uma trajetória de luta pelo desenvolvimento rural sustentável. Brasília: Ipea, 2017, $463 \mathrm{p}$.

SKAR, S.L.; PINEDA-MARTOS, R.; TIMPE, A.; PÖLLING, B.; BOHN, K; KÜLVIK, M.; DELGADO, C.; PEDRAS, C.M.G.; PAÇO, T.A.; CUJIC, M.; TZORTZAKIS, N.; CHRYSARGYRIS, A.; PETICILA, A.; ALENCIKIENE, G.; MONSEES, H.; JUNGE, $R$. Urban agriculture as a keystone contribution towards securing and healthy development for cities in the future. Blue-Green Systems, v. 1, n. 1, p. 1-27, 2020.

UNITED NATIONS. World urbanization prospects: the 2018 revisions. Key factors. Population Division of the UN. Department of Economic and Social Affairs, population division, New York, United Nations, 2019. Disponível em: <https://population.un.org/wup/Publications/Files/WUP2018-Report.pdf>. Acesso: 9 jun. 2020.

VALADARES, Mayara Batista. Análise de aspectos relacionados à segurança alimentar nas hortas comunitárias de Palmas -TO. 2016. 57f. Dissertação (Mestrado) - Programa de Pós-Graduação em Ciência e Tecnologia de Alimentos da Universidade Federal do Tocantins, Campus Universitário de Palmas, 2016. 
Submetido em $18 / 8 / 2020$

Aprovado em 20/12/202O

\section{Sobre o(s) Autor(es):}

\section{Alessandra Polastrini}

Mestre em Desenvolvimento Regional no Programa de Pós-Graduação em Desenvolvimento Regional da Universidade Federal do Tocantins (2020); Especialista em Ensino de Ciências e Biologia (2017) pelo Centro Universitário Claretiano; Graduada em Zootecnia (Bacharelado) pelo Centro Universidade Católica do Tocantins (2011) e Graduação em Ciências Biológicas pelo Centro Universitário Claretiano (2016). Ex-Bolsista da Coordenação de Aperfeiçoamento de Pessoal de Nível Superior (CAPES). Atua na educação básica e superior em disciplinas de agrárias; Desenvolve pesquisas acerca da cadeia de valor, desenvolvimento regional, sustentabilidade e educação. Empresária e Assistente técnica em produção animal. Email: alessandra.polastrini@mail.uft.edu.br

\section{Claudia Regina de Sousa e Silva}

Mestre em Desenvolvimento Regional pela Universidade Federal do Tocantins; Especialista em Gestão Pública e Sociedade pela Universidade Federal do Tocantins; Graduada em Superior de Tecnologia em Gestão Pública pelo Instituto Federal de Educação, Ciência e Tecnologia do Tocantins; Pesquisadora sobre transparência pública, acesso à informação, portais de transparência, governo eletrônico e tecnologia entre outros. Presidente do Observatório Social de Palmas (Tocantins/BR), organização do terceiro setor que busca promover o controle social, a cidadania, o combate à corrupção e a participação popular na gestão pública municipal; Ex-Bolsista de Iniciação Tecnológica do CNPq. Possui experiência em Gestão Pública, Dados Abertos, Lei de Acesso à Informação Transparência Pública, e Combate à Corrupção e, Terceiro Setor entre outros. Email: claudiaregina1106@hotmail.com

\section{João Aparecido Bazolli}

Professor na Universidade Federal do Tocantins (UFT) do Curso de Direito. Docente Permanente do Programa de Pós-graduação em Desenvolvimento Regional (PPGDR/UFT). Pós-doutoramento pela Universidade de Lisboa. Líder do grupo interdisciplinar: Cidade e Meio Ambiente (CNPq). Pesquisador com atuação na linhas (i) regularização fundiária urbana e a segregação socioespacial; (ii) planejamento urbano, mobilidade na cidade e a dicotomia do crescimento urbano desordenado e seu desdobramento à expansão das periferias; (iii) plano diretor, políticas públicas, meio ambiente e sociedade; e (iv) participação social e a democracia direta. Coordenador do (GT-Cidades) no Instituto de Pesquisa, Diretos e Movimentos Sociais (IPDMS). Membro do Núcleo de Estudos Urbanos e das Cidades (Neucidades/UFT). Coordenador Regional (Norte) do Instituto Brasileiro de Direito Urbanístico (IBDU). Membro da Comissão Especial de Planejamento Urbano e Ambiental (CEPUA) do CAU/TO. Coordenador do Laboratório de Cidades (UFT). Obteve distinção de destaque na $2^{\mathrm{a}}$ Edição do Prêmio Esdras de inovação em Ensino do Direito promovido pelo Centro de Ensino e Pesquisa em Inovação da Fundação Getúlio Vargas (FGV) Direito - SP. Atuou pela United Nations Human Settlements Programmepela (UN-HABITAT) no Projeto Global Municipal Database (GMD). Atuou pela New York University no Projeto Pesquisa de Terrenos e Habitação em uma Amostra Global de Cidades - Atlas of Urban Expansion. Obteve distinção honorífica por reconhecida contribuição como Professor Visitante pela Universidad Nacional de Trujillo - Peru. Participou de organização de livros, publicou artigos com resultados de estudos realizados e de projetos de pesquisa e extensão em parcerias nacionais e internacionais. Publicou livro resultado de estudos urbanos, disponível no endereço: https://sites.google.com/view/palmasemfoco. Email: jbazzoli@mail.uft.edu.br 